\section{ABORDAGENS DO BRINCAR EM CURSOS DE GRADUAÇÃO NA ÁREA DA SAÚDE: EDUCAÇÃO FÍSICA, FISIOTERAPIA E TERAPIA OCUPACIONAL}

\author{
APPROACHES TO PLAYING IN UNDERGRADUATE COURSES IN THE AREA \\ OF HEALTH: PHYSICAL EDUCATION, PHYSIOTHERAPY AND OCCUPATIONAL \\ THERAPY
}

\begin{abstract}
ENFOQUES DEL JUEGO EN CURSOS DE GRADO EN EL ÁREA DE LA SALUD: EDUCACIÓN FISICA, FISIOTERAPIA Y TERAPIA OCUPACIONAL
\end{abstract}

Marcos Filipe Guimarães Pinheiro*, Christianne Luce Gomes**
Palavras-chave Jogos e brinquedos. Educação Física Fisioterapia. Terapia Ocupacional.
Keywords

Play and playthings. Physical Education. Physical therapy. Occupational Therapy.

\section{Palabras clave} Juegos y juguetes. Educación Física. Fisioterapia. Terapia Ocupacional.
Resumo: Esta pesquisa teve como objetivo compreender de que maneira o brincar é abordado nos cursos de graduação em Educação Física, Fisioterapia e Terapia Ocupacional da UFMG. Foram realizadas pesquisas bibliográfica e documental. Para a Educação Física, o brincar é observado como linguagem humana e a partir de suas contribuições para a formação humana e para 0 aprendizado e treinamento de modalidades esportivas. Já na Fisioterapia há um viés terapêutico, voltado para reabilitação, em que o brincar é tratado como ferramenta utilizada em alguns momentos do tratamento fisioterápico. A Terapia Ocupacional considera o brincar como atividade, ocupação humana, além de meio médico/terapêutico.

Abstract: This research aimed to understand how playing is approached in Physical Education, Physiotherapy and Occupational Therapy undergraduate courses at UFMG. Bibliographic and document research was conducted. In Physical Education, playing is seen as human language and based on its contributions to human development, learning and sports training. In Physiotherapy there is therapeutic bias, strictly focused on rehabilitation, and playing is only a tool used a few times. Occupational therapy sees play as an activity, as human occupation, as well as a medical/therapeutic medium.

Resumen: Esta investigación tuvo como objetivo comprender de qué manera es abordado el juego en los cursos de Educación Física, Fisioterapia y Terapia Ocupacional de la UFMG. Se ha realizado una investigación bibliográfica y documental. Para la Educación Física el juego es observado como lenguaje humano y a partir de sus contribuciones para la formación humana y para el aprendizaje y entrenamiento en modalidades deportivas. En la Fisioterapia es posible percibir un matiz terapéutico, enfocado en la rehabilitación, donde el jugar es tratado como herramienta que es utilizada en algunos momentos del tratamiento de fisioterapia. A su vez, la Terapia Ocupacional, más allá de los medios médicos/terapéuticos, es un área que también se ha vinculado al juego y a la ludicidad, en cuanto actividades y ocupaciones humanas.
* Centro Universitário Metodista Izabela Hendrix. Belo Horizonte, MG, Brasil.

E-mail: marcosfgpinheiro@gmail.com

** Universidade Federal de Minas Gerais. Belo Horizonte, MG, CNPq Fapemig, Brasil.

E-mail: chrislucegomes@gmail.com

Recebido em: 20-05-2015 Aprovado em: 04-12-2015 (c) (i) () Licence 


\section{INTRODUÇÃO'}

Uma das maneiras mais importantes de o ser humano se relacionar com o mundo, apreendê-lo e compreendê-lo é por meio do brincar, que adquire facetas diferentes no decorrer da vida. Segundo Pereira (2005), por intermédio deste diálogo simbólico abre-se um universo de possibilidades, de leituras, de escolhas, de regras compartilhadas, anunciadas e interpretadas pelos brincantes. $O$ brincar revela que, nas brincadeiras, convive-se com pessoas que não vivem e não agem da mesma forma, mas que participam do mesmo processo de construção sociocultural vivido. Portanto, "o reconhecimento da pluralidade, ou seja, da diversidade das vivências lúdicas, abre um caminho educativo importante para a compreensão das diferenças entre os sujeitos" (PINTO, 2007, p. 180).

Para vários autores (tais como DEBORTOLI, 1999, GOMES, 2004, PEREIRA, 2005), a ludicidade é uma forma de linguagem, ou seja, uma maneira de o ser humano se expressar, referenciada no brincar, na brincadeira. Segundo Debortoli (1999) o brincar, a brincadeira e o gesto lúdico são possibilidades de expressão, representação, (res)significação, e (re) interpretação da e na cultura. 0 autor esclarece que a ludicidade é a capacidade de se brincar com a realidade. "Por isso a linguagem lúdica ou gesto lúdico é a expressão do sujeito criador, capaz de ressignificar o mundo, ou até mesmo transformá-lo" (DEBORTOLI, 1999, p. 115).

Assim como outras possibilidades de experiência humana, o brincar pode ser visto como ferramenta ou como expressão (PEREIRA, 2005). Dessa maneira, brinca-se por brincar, brinca-se para aprender, brinca-se para "sarar". Desse modo, o brincar vem sendo valorizado e utilizado como poderosa ferramenta. Vários campos de intervenção, como a Pedagogia, a Psicologia, a Educação Física, a Fisioterapia e a Terapia Ocupacional, lançam mão desse recurso durante as práticas profissionais cotidianas.

Como mostra Pereira (2005), qualquer objeto pode se tornar um brinquedo. Não existe artefato lúdico, mas uma relação lúdica que cada indivíduo pode estabelecer com outras pessoas e com objetos. Por tudo isso, o brincar, os jogos e as brincadeiras, seus usos e significados passam a ser alvo de debate, intervenções e estudos acadêmicos de diversos campos do conhecimento. A Educação Física, a Fisioterapia e a Terapia Ocupacional, além de outras áreas já citadas, muitas vezes abordam o tema do brincar no currículo de seus cursos de formação.

Em face dessas considerações iniciais, este artigo objetiva compreender de que maneira a temática do brincar é abordada no âmbito do ensino nos cursos de graduação em Educação Física, Fisioterapia e Terapia Ocupacional da Escola de Educação Física, Fisioterapia e Terapia Ocupacional (EEFFTO) da UFMG.

\section{METODOLOGIA}

Esta investigação de natureza qualitativa combinou a pesquisa bibliográfica e a pesquisa documental. A primeira foi realizada principalmente por meio de livros, entretanto, também 
foram utilizados artigos, teses e dissertações, entre outras fontes. A pesquisa documental foi realizada com base na análise dos projetos político-pedagógicos dos cursos e dos programas das disciplinas obtidos por meio de solicitações feitas aos colegiados e departamentos dos cursos.

Foi estabelecido como critério de inclusão dos cursos de graduação participantes fazer parte da EEFFTO, unidade institucional da UFMG em que estão alocados os únicos cursos do país de Mestrado e Dourado em Lazer. Tais cursos têm promovido a produção de conhecimento sobre o brincar, entre outros temas relevantes ao campo do Lazer no Brasil.

A partir daí foram analisados o título de cada disciplina, a ementa, os conteúdos programáticos, os objetivos e as referências, além de outras informações relevantes. Para isso, as buscas focalizaram termos como brincar, brincadeira(s), brinquedo(s), lúdico(a) e jogo(s).

A fim de melhor compreender a inserção da temática nos currículos desses três cursos, os documentos selecionados foram analisados à luz das teorias e dos conceitos apresentados durante a pesquisa bibliográfica, por meio da construção iterativa de uma explicação. Esta estratégia faz parte do modelo de análises qualitativas de conteúdo propostas por Laville e Dionne (1999). De acordo com esses autores, a análise qualitativa de conteúdo permite que 0 (a) pesquisador(a) se prenda

às nuanças de sentido que existem entre essas unidades, aos elos lógicos entre essas unidades [...] visto que a significação de um conteúdo reside largamente na especificidade de cada um de seus elementos e na relação entre eles, especificidade que escapa amiúde ao domínio do mensurável (LAVILLE; DIONNE, 1999, p. 227).

Como mostra Foucault (2006), uma das formas de o poder se estabelecer e funcionar é através da produção, acumulação, circulação e funcionamento do discurso que o produz e que o reproduz. Dessa maneira, o currículo constrói identidades e subjetividades. A partir da abordagem e do ensino de uma determinada temática, um conteúdo biomédico, bem como pela exclusão desses saberes, espera-se (re)formar determinado indivíduo. Em currículos, sobretudo de formação profissional, é possível moldar interesses, perspectivas e atitudes. "Junto com os conteúdos das disciplinas escolares, se adquirem na escola percepções, disposições e valores que orientam os comportamentos e estruturam as personalidades" (PARAÍSO; SANTOS, 1996, p. 35).

\section{RESULTADOS E DISCUSSÃO}

O quadro a seguir apresenta, em ordem alfabética, todas as disciplinas de cada departamento cujos programas explicitam algum(ns) dos termos utilizados como critério de busca e que, por este motivo, foram selecionadas. Assim, foram identificadas 17 disciplinas com temáticas relacionadas ao brincar, ministradas nos currículos dos três cursos estudados. 
Quadro 1 - Disciplinas selecionadas por Departamento/Curso e termo/s encontrado/s

\begin{tabular}{|c|c|}
\hline DEPARTAMENTO DE ESPORTES/EDUCAÇÃO FÍSICA & TERMO ENCONTRADO \\
\hline Antropologia e Educação Física & Lúdico \\
\hline Ensino de Handebol & Jogo; brincando \\
\hline Ensino do Voleibol & Jogo \\
\hline Ginástica & Brincadeiras lúdicas \\
\hline Teoria e prática dos esportes I & Jogo \\
\hline Teoria e prática dos esportes II & Jogo \\
\hline DEPARTAMENTO DE EDUCAÇÃO FÍSICA/EDUCAÇÃO FÍSICA & TERMO ENCONTRADO \\
\hline Ensino de jogos, brinquedos e brincadeiras & Brincadeiras; brinquedos; jogos \\
\hline Questão afetiva e social da Educação Física & Brincar \\
\hline DEPARTAMENTO DE FISIOTERAPIA/FISIOTERAPIA & TERMO ENCONTRADO \\
\hline Fisioterapia aplicada à Pediatria II & Brincar; brincadeiras \\
\hline Movimento e desenvolvimento humano II & Brinquedo; brincadeiras \\
\hline $\begin{array}{c}\text { DEPARTAMENTO DE TERAPIA OCUPACIONAL/TERAPIA } \\
\text { OCUPACIONAL }\end{array}$ & TERMO ENCONTRADO \\
\hline Atividade e desenvolvimento humano I & Brincar; brinquedos; jogos \\
\hline Atividade e desenvolvimento humano II & Atividades lúdicas; jogos; brincadeiras \\
\hline Cinesioterapia - Terapia Ocupacional & Brincando \\
\hline Recursos Terapêuticos I & Brinquedos \\
\hline Recursos Terapêuticos II & Jogos \\
\hline Teoria de Jogos & Brincar \\
\hline Terapia Ocupacional aplicada à saúde mental e à psiquiatria & Brinquedo; jogo \\
\hline
\end{tabular}

Fonte: Elaboração própria.

Da graduação em Educação Física, considerando os dois departamentos existentes Departamento de Educação Física e Departamento de Esportes -, foram obtidos 65 programas de disciplinas e selecionados oito para serem analisados, pois a maioria não tratava das temáticas centrais da pesquisa.

$\mathrm{Na}$ análise desses oito programas de disciplinas foi possível verificar que o termo jogo, na maioria das vezes, é utilizado como sinônimo de esporte, ou das atividades de ensino e prática de determinada modalidade esportiva. Os "objetivos" explicitados nos programas de seis disciplinas do Departamento de Esportes estão relacionados com o ensino de modalidades esportivas e voltados para os processos de treinamento dessas modalidades, enfatizando assim os aspectos técnicos, táticos e psicológicos do jogo esportivo. Isso pode ser evidenciado, por exemplo, nas ementas, nos objetivos e nos conteúdos dos programas de disciplinas que focalizam o ensino de aspectos técnico-táticos de esportes por meio de "brincadeiras" e demais atividades tidas como "lúdicas" (PINHEIRO, 2009).

Em apenas uma disciplina, intitulada "Ensino de jogos, brinquedos e brincadeiras", 0 termo jogo é tratado como sinônimo de brincadeira e o brincar é abordado como objeto de estudos e intervenção numa perspectiva sociocultural que Ihe é própria.

Debortoli $(2004$, p. 20) esclarece que toda brincadeira consiste num jogo, no sentido de construção, instauração e partilha de certas regras, por mais tácitas que sejam, e de uma dinâmica coletiva de significação. Todavia, nem todo jogo é uma brincadeira. "Nem todo jogo se expressa como possibilidade de reconstrução e ressignificação da realidade." 
Já os termos lúdico, brincadeira, ou brincar, são utilizados, aparentemente, como elemento motivacional, prazeroso e minimizador do caráter maçante de exercícios repetitivos para a aprendizagem e treinamento. Isso aparece claramente em expressões presentes nos "conteúdos" da disciplina como "brincando e aprendendo handebol" (disciplina Ensino de Handebol), ou "brincadeiras lúdicas de aquecimento" (disciplina Ginástica). De acordo com Debortoli (2004), as brincadeiras pedagógicas são aquelas que se esforçam para dar um tom mais agradável àquilo que se quer ensinar. Tal discurso carrega consigo o paradoxo de que o que se tem para fazer, para se conhecer e aprender é tão monótono que é preciso outra roupagem para se tornar mais agradável.

Assim, percebe-se que o tema brincar possui pontos de intercessão com outras temáticas, como o ensino, a prática e 0 treinamento de modalidades esportivas. Embora 0 brincar apareça como conteúdo principal em apenas uma disciplina, são muitas as possibilidades de inserção da temática nos programas dessas disciplinas, podendo ser desenvolvido sob diversos aspectos e contextos. Tais disciplinas tratam de outras temáticas mais específicas, como os esportes, mas fazem relação com a ludicidade, o brincar, os brinquedos e as brincadeiras, a diversão, etc. Entretanto, Debortoli (2004, p. 20) afirma que termos como brincar e brincadeira são mais do que simples conceitos, "materializam-se como concepções e princípios profundamente complexos". É necessário atentar, portanto, para o uso que se faz de tais conceitos e atividades.

Alguns discursos correntes transformam o brincar, o brinquedo e a brincadeira em artefatos de reprodução de estruturas, padronizados para comportamentos futuros. $\mathrm{Na}$ tentativa de dar estatuto de importância ao brincar, toma-se como referência aquilo que é considerado relevante. Por exemplo, o esporte de alto rendimento, ou o trabalho, a ciência, conhecimentos como os da matemática, da leitura e escrita, ou, ainda, comportamentos disciplinados considerados como adequados. De acordo com o autor, a brincadeira, enquanto princípio e concepção, lembra a riqueza, a diversidade e as múltiplas maneiras de produção dos sentidos, da história e da humanidade.

Nesse sentido, observa-se como a Educação Física, enquanto campo de discussão do brincar, vem possibilitando o tratamento dessa temática especificamente e, também, por intermédio de temas relacionados.

Por sua vez, o colegiado do curso de graduação em Fisioterapia da UFMG enviou os programas completos de 52 disciplinas, obrigatórias e optativas. Entretanto, apenas duas disciplinas, como visto no Quadro 1, apresentaram como um de seus "conteúdos programáticos" o brincar e as brincadeiras - ambos concebidos como recursos terapêuticos à pediatria. A ideia de brincar apresentada nos programas relaciona-se com disfunções a serem tratadas a partir de tais atividades, consideradas, de maneira limitada, "típicas das crianças", como apontado no programa da disciplina intitulada "Fisioterapia aplicada à pediatria II".

Pereira (2005) mostra que a brincadeira auxilia na constituição do ser humano independentemente da idade que tenha. Embora o brincar nos remeta à infância, podendo se expressar nas/pelas crianças em suas formas mais genuínas, a brincadeira não é algo próprio, nem tampouco exclusivo das crianças. Faz parte da necessidade humana de explorar simbolicamente o mundo, potencializando as mais diversas representações do real e construções da realidade. 
Apesar de vários(as) autores(as),2 em diferentes campos do conhecimento, como a Psicologia, a Terapia Ocupacional e a própria Fisioterapia, trabalharem com o brincar e a brincadeira enquanto um comportamento observável, algumas considerações devem ser feitas. O brincar, nessa perspectiva, pode deixar de ser usado como fonte de criação e produção do mundo, passando a ser considerado a partir de atitudes e comportamentos padronizados e esperados. Dessa maneira, na prática terapêutica, o brincar pode correr o risco de perder parte importante de sua dimensão simbólica, de sua expressão como "linguagem e como processo de elaboração de significados e sentidos coletivos, contextualizados e enraizados no universo social que o legitima" (DEBORTOLI, 2004, p. 20).

A prática terapêutica da Fisioterapia poderia ser repensada constantemente no sentido de humanizá-la, como apontam Blascovi-Assis, Peixoto e Reis (2001). Entretanto, uma das barreiras enfrentadas é a supervalorização dos conteúdos tidos como terapêuticos nos cursos de graduação, não só da Fisioterapia, mas na área da saúde de uma forma geral, a partir de uma concepção limitada de saúde. A necessidade de manutenção da saúde e bem-estar da população, onde a saúde torna-se objetivo geral e dever de cada indivíduo, trouxe uma súbita importância para a medicina (FOUCAULT, 2006) e, posteriormente, para áreas que nasceram sob a influência médica.

Dessa maneira, pode-se observar o caráter curativo e reabilitador da formação desses(as) profissionais. No contexto da Fisioterapia, isso vai ao encontro da legislação vigente que regula a área, tanto no âmbito da formação, como, e principalmente, da sua atuação. No Decreto-Lei 938 , art. $3^{\circ}$, encontra-se que

\begin{abstract}
é atividade privativa do fisioterapeuta executar métodos e técnicas fisioterápicos com a finalidade de restaurar, desenvolver e conservar a capacidade física do ciente." Nesse sentido, o Parecer $n^{\circ}$ 388/63 destaca a participação dos, até então, denominados Técnicos em fisioterapia e terapia ocupacional, exclusivamente na aplicação de técnicas e exercícios recomendados pelos médicos, que busquem a cura e/ou a "recuperação dos parcialmente inválidos para a vida social. (BRASIL, 1969).
\end{abstract}

"Os documentos oficiais relativos ao profissional de Fisioterapia, com exceção, talvez, do seu Código de Ética Profissional, parecem ter sido elaborados sob a ótica da concepção saúde-doença", conforme apontam Rebelatto e Botomé (1999, p. 63). Os autores ressaltam, ainda, que tais documentos, em nenhum momento, citam ou deixam transparecer "os diversos níveis, tipos ou âmbitos de atuação que esse profissional poderia ou deveria exercer ao atuar na 'assistência' às condições de saúde de um indivíduo ou de uma comunidade". Portanto, entendem que o ensino superior não pode ser apenas um espaço para o ensino de técnicas e capacidades para o auxílio a outros(as) profissionais.

Blascovi-Assis, Peixoto e Reis (2001) chegam a apontar o(a) fisioterapeuta como um(a) educador(a). Educam-se "os hábitos posturais, as rotinas de estimulação ao desenvolvimento, a disposição de mobiliários em indústrias ou em residências, o tipo de brinquedo, roupa ou acessório" que facilite e promova a independência no cotidiano. Mas, nos currículos deste curso, "por estar caracteristicamente vinculado à saúde, pouca ênfase tem sido dada à sua formação enquanto educador" (BLASCOVI-ASSIS; PEIXOTO; REIS, 2001, p. 128). Olhando além de técnicas, tem-se um papel formador de pessoas mais capacitadas para tratar dignamente seus pacientes, atuando na comunidade como agentes educadores, quer voltados para a reabilitação, quer para a prevenção em diferentes níveis.

2 Carvalho et al. (2005) apresentam uma série de estudos contemplando diferentes abordagens do brincar e da brincadeira. 
As autoras apresentam um projeto de humanização no campo da Fisioterapia onde mostram serem necessários novos perfis na formação universitária da Fisioterapia. A terapia deve ser um lugar agradável e não de desprazer. Um paciente motivado, além de não abandonar o tratamento, se envolve nele e recupera-se mais rapidamente. Considerando a graduação, "algumas disciplinas relacionadas à formação educacional deste profissional acabam sendo pouco valorizadas pelos próprios docentes, ficando a grande ênfase naquelas que proporcionam um enfoque essencialmente médico" (BLASCOVI-ASSIS; PEIXOTO; REIS, 2001, p. 128).

Numa concepção ampliada da relação saúde-doença, estão envolvidos de forma complexa diversos aspectos psicológicos, físicos, sociais e ambientais da condição humana e de atribuições de significado. Saúde e doença são fenômenos clínicos e sociológicos, pois são vividos culturalmente, experimentados e ressignificados pela sociedade. Assim, saúde e doença "importam tanto pelos seus efeitos no corpo como pelas suas repercussões sobre 0 imaginário: ambos são reais em suas consequências" (MINAYO, 2004, p. 16).

Portanto, não é possível, como destaca essa autora, dissociar-se de qualquer forma de tratamento, de qualquer procedimento terapêutico, os aspectos subjetivos das pessoas, seus valores, anseios, medos e crenças. Negligenciando ou silenciando temas socioculturais, como o brincar, no currículo, a Fisioterapia pode correr o risco de formar profissionais cada vez mais sob uma perspectiva médica tradicional. Há, portanto, para o currículo da graduação em Fisioterapia, perspectivas reais de uma maior humanização, e o brincar pode ser um dos caminhos possíveis.

Em um conto de Walter Benjamin é possível visualizar outras possibilidades que vão além das técnicas curativas tradicionais do saber médico.

A criança está doente. A mãe a leva pra cama e se senta ao lado. E então começa a lhe contar histórias. Como se deve entender isso? [...] Também já se sabe como o relato que o paciente faz ao médico no início do tratamento pode se tornar o começo de um processo curativo. Daí vem a pergunta se a narração não formaria o clima propício e condição mais favorável de muitas curas, e mesmo se não seriam todas as doenças curáveis se apenas deixassem flutuar para longe - até a foz - na correnteza da narração. Se imaginarmos que a dor é uma barragem onde se opõe à correnteza da narrativa, então vemos claramente que é rompida onde sua inclinação se torna acentuada o bastante para largar tudo o que encontra em seu caminho ao mar ditoso do esquecimento. É o carinho que delineia um leito para essa corrente (BENJAMIN, 1994, p. 269).

Abordando a temática do lazer em um ambiente hospitalar, Pinto (2009) destaca os diversos papéis que as atividades lúdicas, as brincadeiras e os jogos podem adquirir num contexto de sofrimento. Dentre as várias possibilidades apontadas pela autora, ela percebeu, no caso específico do hospital, a ocupação do tempo, a liberação da dor, o relaxamento, a fuga do tédio, entre outras. Questões que, apesar de legítimas, considerando este contexto, podem ser ampliadas. Assim, todos esses aspectos podem ser complementares à ideia de ressignificação do brincar, de desenvolvimento pessoal e social.

Finalmente, considerando o curso de Graduação em Terapia Ocupacional, das 53 disciplinas acessadas, sete foram selecionadas e analisadas. Dessas disciplinas, cinco trazem a possibilidade de um estudo mais consistente sobre a temática do brincar no currículo. Como já mencionado, esta possibilidade também foi identificada no currículo da Educação Física, uma vez que o tema é abordado de uma forma direta, enquanto objeto de estudo, como, por 
exemplo, na disciplina "Teoria de Jogos". De acordo com Drummond e Costa (2010) foi a partir da década de 1970, ao considerar as ocupações humanas de uma forma geral, que a Terapia Ocupacional passou a problematizar atividades diversas do cotidiano como o trabalho, o estudo, o brincar e as denominadas Atividades de Vida Diária (AVDs).

Foi possível identificar inúmeras ocorrências dos termos lúdico (ludicidade), jogo, brinquedo, brincar e brincadeiras, superando até mesmo a quantidade de registros encontrados nas disciplinas do currículo da Educação Física (como mostrado no Quadro 1). Entretanto, estes termos, que também foram encontrados em ementas, eram tratados como sinônimos e, infelizmente, indicavam pouco aprofundamento nos "conteúdos" apresentados nos programas. Todavia, na Terapia Ocupacional, bem como na Fisioterapia, também é possível perceber em alguns momentos o caráter terapêutico nas ações do brincar, como nos casos das disciplinas "Recursos Terapêuticos I" e "Recursos Terapêuticos II". Em tais disciplinas o brincar, enquanto ocupação humana, pode ser mensurado e avaliado por meio de escalas, testes e avaliações, principalmente na infância.

Respondendo a pergunta "Por que avaliar o brincar?", Rezende (2008) considera que observar e fazer medições do brincar do indivíduo pode facilitar o tratamento, uma vez que fornece valiosas informações sobre as competências cognitivas, motoras e sociais, além de refletir o processo de desenvolvimento. Ao citar algumas formas de intervenções terapêuticas, a autora mostra que o brincar enquanto modalidade terapêutica é comum nos casos de atendimento de crianças com deficiência grave. $O$ que pode ser confirmado na análise do programa da disciplina "Terapia Ocupacional aplicada à saúde mental e à psiquiatria". Além disso, a atuação profissional também pode focar a habilidade de brincar quando a criança apresenta um pobre repertório de habilidades, o que pode comprometer seu desempenho.

Com isso, ainda de acordo com a autora, pode-se estimular e desenvolver, por exemplo, aspectos posturais, a coordenação motora, a concentração e a interação com pessoas e objetos. A partir daí, a Terapia Ocupacional propicia o auxílio no desenvolvimento ocupacional de crianças nas atividades de brincar. Segundo Rezende (2008), as crianças de uma forma geral respondem a estímulos ambientais, sociais, entre outros. Uma vez detectada alguma dificuldade nesse processo, sobretudo com crianças deficientes, estas podem "precisar de ajuda até para brincar" (REZENDE, 2008, p. 42). Essa atenção especial dada ao brincar, principalmente pela Terapia Ocupacional, revela a importância atribuída à "atividade", o que, do ponto de vista deste trabalho, corrobora a ideia do brincar, enquanto uma necessidade do ser humano, e pôde ser observada, por exemplo, ao se analisar os programas das disciplinas "Atividade e desenvolvimento humano I" e "Atividade e desenvolvimento humano II".

Como lembra Debortoli (2004), apesar de se reconhecer a importância e a legitimidade de tais intervenções terapêuticas, enquanto especificidades da Terapia Ocupacional, é preciso evitar o risco de anular o brincar enquanto expressão humana de significados. E isso pode acontecer ao se esperar do brincar, e em determinadas brincadeiras, atitudes e comportamentos prontos, predeterminados, ao se abordar a pessoa como mero objeto de investigação. Ao buscar o lugar que o brincar pode assumir no contexto da infância, o autor ainda pondera que é preciso ressignificar a visão e o lugar ocupado socialmente pela criança: "sua formação e seu desenvolvimento, suas aprendizagens e compreensão do mundo", sua expressão enquanto sujeito, constituído numa subjetividade completa e própria. Com "sua palavra, sua gestualidade, suas relações intersubjetivas, sua contraditoriedade, sua humanidade" (DEBORTOLI, 1999, p. 109). 
Todavia, no Brasil, ainda não é comum a utilização de instrumentos para a avaliação do brincar. Assim, como ressalta Rezende (2008, p. 33) o(a) terapeuta ocupacional "deve escolher bem os instrumentos para avaliar o brincar sem desconsiderar os componentes que possam contribuir ou interferir no seu desempenho, seja na criança, no ambiente ou na demanda da tarefa".

Com certa divergência da perspectiva da Terapia Ocupacional, Debortoli (1999) problematiza o fato de a criança ainda ser vista sistematicamente como um ser imperfeito $e$ dependente. Ela é abordada como um mero objeto de investigação. "É sempre colocada em relação ao mundo social do adulto, que 'nessa criança' projeta seus ideais, desconsiderando-a como sujeito pensante e desejante, que se constrói historicamente no interior de uma cultura específica" (DEBORTOLI, 1999, p. 108).

Considerando práticas curriculares da formação em Terapia Ocupacional, previstas em alguns conteúdos programáticos das disciplinas, observa-se a ênfase dada ao aspecto lúdico e de valorização do brincar. O brincar e o jogo lúdico, de acordo com Pinto (2007), assim como os corpos, são construções socioculturais históricas, que influenciam e/ou são influenciadas pela vida social e cultural mais ampla em que acontece. E essa vivência plural e significativa tem como referência a humanização, participando da construção de memórias e identidades. "As pessoas que brincam juntas gostam de coisas parecidas, enfrentam problemas do mesmo tipo, festejam do mesmo jeito" (PINTO, 2007, p. 180).

Apesar da intensa formação biomédica, vê-se o esforço da Terapia Ocupacional, como visto na disciplina "Teoria de jogos", por debruçar-se em outros aspectos que compõem a vida humana inserida num determinado contexto, tais como sociológicos, antropológicos e econômicos (DRUMMOND; MAGALHÃES, 2001).

Desse modo, de acordo com as características e especificidades de cada área tem-se uma dada ênfase no trato com o brincar. Afinal, no interior de cada curso o currículo vai sendo construído em jogos de interesses, intermediados por relações de poder. Atividades de cunho terapêutico, atividades educativas, esportivas e de lazer, dentre outras, podem comportar 0 brincar, as brincadeiras e os brinquedos.

\section{CONSIDERAÇÕES FINAIS}

De acordo com Baudrillard (1995), a prática medical não tem perdido sua superioridade. "Apesar de 'democraticamente consumida', a medicina nada perdeu do seu sagrado e da sua funcionalidade mágica" (BAUDRILLARD, 1995, p. 148). Isso pode ser constatado desde os períodos iniciais desses três cursos de graduação abordados neste estudo, porém, talvez seja mais evidenciado, atualmente, no contexto da Fisioterapia, como pode ser percebido na ênfase privilegiada dos conteúdos biomédicos de seu currículo formal.

Não há problemas, obviamente, em se trabalhar o processo saúde-doença nas disciplinas e currículos de cursos que, afinal, estão inseridos na área da saúde. Todavia, o desafio é tratar deste processo de forma ampliada, por exemplo, reconhecendo o lazer - onde o brincar se manifesta - como um dos determinantes da saúde. Essa compreensão é apontada por alguns documentos públicos, entre eles o artigo 3o da Lei ํㅜ. 8.080 (BRASIL, 1990), e a recente Política Nacional de Promoção da Saúde (BRASIL, 2006). Tais documentos afirmam 0 
lazer como um dos fatores determinantes e condicionantes da saúde. Embora haja referências legais para a promoção do lazer no âmbito da saúde, Pinto (2009, p. 168) chama a atenção para o fato de que "a formação profissional em saúde pouco esclarece sobre a importância do lazer e sobre as suas contribuições para a vida das pessoas".

Em qualquer ação de planejamento, profilaxia ou de tratamento, na relação saúdedoença, deveriam ser considerados os valores, desejos, expectativas, atitudes e crenças dos grupos a quem a ação se dirige (MINAYO, 2004). Porém, na busca da valorização pela comunidade cientifica, muitos campos de conhecimento e de atuação, sobretudo na grande área da saúde, apegam-se aos conhecimentos biomédicos em detrimento dos demais.

Foucault (2006) nos mostra que, para gerar efeitos de poder, é intenção menosprezar um sujeito ou um saber para que se possa entronizar outros; fato ocorrente, também, no âmbito das disciplinas e conteúdos curriculares. Assim, são deixados de lado alguns saberes e conhecimentos sócio-históricos, político-culturais, entre outros, que permeiam o universo das relações humanas em sociedade.

Como comenta Carvalho (2005), vivenciar a dimensão lúdica da vida, estimular a capacidade criativa e inventiva das pessoas e dos grupos - por meio das atividades esportivas, do teatro, das atividades artísticas, dos jogos e das brincadeiras - é investir na qualidade de vida e nas condições de saúde. Tais investimentos, como tratado neste artigo, se mostram possíveis de serem desenvolvidos ao longo dos processos de formação profissional nessas três áreas, respeitando e considerando as características específicas e particulares de cada uma.

Assim, seja na busca pelo brincar, pelo simples fato de brincar, pelas brincadeiras com fim em si mesmas, pela promoção de atividades com objetivos de desenvolver atitudes críticas e/ou criativas; ou então, por intermédio dessas atividades, com o escopo de apenas minimizar uma dor ou uma deficiência qualquer, de contribuir para uma "aceitação" de determinada situação ou de um tratamento, o brincar se revela possível.

\section{REFERÊNCIAS}

BAUDRILLARD, Jean. A sociedade de consumo. Lisboa: Edições 70, 1995.

BENJAMIN, Walter. Rua de mão única. 4. ed. São Paulo: Brasiliense, 1994.

BLASCOVI-ASSIS, Silvana M.; PEIXOTO, Beatriz O.; REIS, Conceição A. S. O grupo

Fisioalegreterapia e a preocupação com a motivação nos atendimentos terapêuticos. Licere, Belo Horizonte, v. 4, n. 1, p. 127-134, 2001.

BRASIL. Decreto-Lei no 938, de 13 de outubro de 1969. Disponível em: <http://www.planalto.gov.brl ccivil 03/decreto-lei/1965-1988/Del0938.htm>. Acesso em: 26 out. 2009.

BRASIL. Lei no $\mathbf{8 0 8 0}$, de 19 de setembro de 1990. Dispõe sobre as condições para a promoção, proteção e recuperação da saúde, a organização e o funcionamento dos serviços correspondentes e dá outras providências. Disponível em: <http://portal.saude.gov.br/portal/arquivos/pdf/LEl8080.pdf>. Acesso em: 26 out. 2009.

BRASIL. Ministério da Saúde. Secretaria de Vigilância em Saúde. Política nacional de promoção da saúde. Brasília: Ministério da Saúde, 2006.

CARVALHO, Yara M. et al. Lazer e saúde. Brasília: SESI/DN, 2005. 
DEBORTOLI, José A. Brincadeira. In: GOMES, Christianne L. (Org). Dicionário crítico do lazer. Belo Horizonte: Autêntica, 2004. p. 19-24.

DEBORTOLI, José A. Com olhos de crianças: a ludicidade como dimensão fundamental da construção da linguagem e da formação humana. Licere, Belo Horizonte, v. 2, n. 1, p. 105-117, 1999.

DRUMMOND, Adriana F.; COSTA, Carmen T. Formação profissional em terapia ocupacional e suas interfaces com o lazer. In: ISAYAMA, Hélder F. (Org.). Lazer em estudo: currículo e formação profissional. Campinas: Papirus, 2010. p. 185-203.

DRUMMOND, Adriana F.; MAGALHÃES, Lívia C. Tendências da formação do terapeuta ocupacional no Brasil. Revista de Terapia Ocupacional da Universidade de São Paulo, São Paulo, v. 12, n. 1/3, p. 34-39, jan./dez. 2001.

FOUCAULT, Michel. Microfísica do poder. 22. ed. Rio de Janeiro: Edições Graal, 2006.

GOMES, Christianne L. Lúdico. In: GOMES, Christianne L. (Org). Dicionário crítico do lazer. Belo Horizonte: Autêntica, 2004. p. 141-146.

LAVILLE, Christian; DIONNE, Jean. A construção do saber: manual de metodologia da pesquisa em ciências humanas. Porto Alegre: Artmed, 1999.

MINAYO, Maria C. S. 0 desafio do conhecimento: pesquisa qualitativa em saúde. 8. ed. São Paulo: Hucitec, 2004.

PARAÍSO Marlucy A.; SANTOS, Lucíola L. C. Dicionário crítico da educação: Currículo. Presença Pedagógica, Belo Horizonte, v. 2, n. 7, jan./fev. 1996.

PEREIRA, Eugênio T. Brincar e criança. In: CARVALHO, Alysson M. et al. Brincar(es). Belo Horizonte: Editora UFMG, 2005. p. 17-27.

PINHEIRO, Marcos F. G. Inserção da temática lazer nos currículos dos cursos de graduação em Educação Física, Fisioterapia e Terapia Ocupacional da Universidade Federal de Minas Gerais. 2009. Dissertação (Mestrado) - Escola de Educação Física, Fisioterapia e Terapia Ocupacional, Universidade Federal de Minas Gerais, Belo Horizonte. 2009.

PINTO, Gabriela B. 0 lazer em hospitais: realidades e desafios. 2009. Dissertação (Mestrado) Escola de Educação Física, Fisioterapia e Terapia Ocupacional, Universidade Federal de Minas Gerais, Belo Horizonte. 2009.

PINTO, Leila M. S. M. Vivência lúdica no lazer: humanização pelos jogos, brinquedos e brincadeiras. In: MARCELLINO, Nelson C. Lazer e cultura. Campinas: Alínea, 2007. p. 171-194.

REBELATTO, José R.; BOTOMÉ, Sílvio P. Fisioterapia no Brasil: fundamentos para uma ação preventiva e perspectivas profissionais. 2. ed. São Paulo: Manole, 1999.

REZENDE, Márcia B. O brincar e a intervenção da Terapia Ocupacional. In: DRUMMOND, Adriana F; REZENDE, Márcia B. (Orgs.) Intervenções da terapia ocupacional. Belo Horizonte: Editora UFMG, 2008. p. 25-44. 
